\title{
ALDH1 as a prognostic marker for lymph node metastasis in OSCC
}

\author{
CAROLIN GÖTZ ${ }^{1}$, OLIVER BISSINGER ${ }^{1}$, CHRISTOPHER NOBIS ${ }^{1}$, \\ KLAUS DIETRICH WOLFF ${ }^{1}$, ENKEN DRECOLL ${ }^{2}$ and ANDREAS KOLK ${ }^{1}$ \\ ${ }^{1}$ Department of Oral and Maxillofacial Surgery; ${ }^{2}$ Institute of Pathology, Klinikum Rechts der Isar, \\ Technical University of Munich, D-81675 Munich, Germany
}

Received February 12, 2018; Accepted June 5, 2018

DOI: $10.3892 /$ br.2018.1131

\begin{abstract}
Long-term survival in cases of head and neck squamous cell carcinoma, particularly oral squamous cell carcinoma (OSCC), remains a rare achievement in the field of clinical oncology. In recent years, the theory of cancer stem cells (CSCs) has emerged and been used to offer explanations for tumour recurrence and metastasis. The present aim was to investigate the role of aldehyde dehydrogenase 1 (ALDH1) as a CSC-marker for OSCC and to determine the role of p16 ${ }^{\text {ink4a }}$, which is also a surrogate marker of human papilloma virus (HPV), in the expression of ALDH1. The study cohort comprised of 186 surgically-treated cases of OSCC. The primaries were located in the oral cavity. The expression of the CSC marker (CSCM) ALDH1 was evaluated via immunohistochemistry (IHC) of a tissue microarray. HPV detection was performed by polymerase chain reaction and an HPV Array kit. Furthermore, the IHC expression of p16 ${ }^{\text {ink4a }}$ was also analysed. Risk regression models as the Kruskal Wallis test was used to assess the association of CSCM and p16 ${ }^{\text {ink4a }}$ expression with tumour size and lymph node metastasis, and cox proportional hazards were analysed. Additionally, coexpression of the markers ALDH1 and p16 ${ }^{\text {ink4a }}$ was analysed with regard to associations with tumour classification. Overall, high expression of ALDH1 in lymph nodes was significantly associated with Union for International Cancer Control (UICC) stage IV $(\mathrm{P}=0.044)$ and $\mathrm{T} 4$ stage cancer $(\mathrm{P}=0.03)$. p16 ${ }^{\text {ink } 4 a}$ positivity, in cases of HPV negativity, was associated with worse survival rate compared with that of the total cohort $(\mathrm{P}=0.048)$. Collectively the data indicate that ALDH1 expression may be suitable for detection of unfavourable prognosis in OSCC patients, based in part on its apparent role as a marker of metastasis. HPV status was not statistically predictive of
\end{abstract}

Correspondence to: $\mathrm{Dr}$ Carolin Götz, Department of Oral and Maxillofacial Surgery, Klinikum Rechts der Isar, Technical University of Munich, 22 Ismaninger Street, D-81675 Munich, Germany

E-mail:cg.goetz@tum.de

Key words: aldehyde dehydrogenase 1, lymph node metastasis, oral squamous cell carcinoma, cancer stem cells patient outcome or CSCM expression; however, p16 ${ }^{\text {ink4a }}$ remains a potential marker in HNSCC Further in vitro studies with ALDH1 and p16 ${ }^{\text {ink4a }}$ should be performed to evaluate the expression of ALDH1 and HPV in cell culture and to clarify the role of ALDH1 as a marker for increased invasiveness of OSCC cells.

\section{Introduction}

Head and neck cancer (HNC) is the seventh most common malignancy worldwide in men and also the thirteenth most common in women (1). HNC may be subdivided into oral, oropharyngeal, laryngeal and skin cancers (2). Squamous cell carcinoma of the head and neck (HNSCC) is the most common histopathological diagnosis within these subgroups. Alcohol and tobacco consumption are risk factors for carcinogenesis (3). Sun light exposure also has an impact on the development of skin cancer in the head and neck area (4). In the last decade, human papilloma virus (HPV) has also emerged as an aetiological factor in the development of HNSCC (5).

Oral squamous cell carcinoma (OSCC) has the second worst prognosis after laryngeal squamous cell carcinoma among HNCs; laryngeal squamous cell carcinoma has a progression-free 5 year survival $<50 \%$, while the progression-free 5 year survival of OSCC is $<70 \%$ (6). Extended tumour growth and lymph node metastasis are frequently detected at primary diagnosis (7). Surgical treatment options to reconstruct the complex anatomy of the head and neck are available. Adequate functional recovery may be achieved with use of reconstructive microvascular flaps combined with sufficient maintenance of health following surgery (8). Nevertheless, recurrence and metastasis generally occurs in $25 \%$ of patients following operative treatment with curative intention (9). Treatment possibilities in cases of recurrence or metastasis are limited and no marked improvement of survival probability has been achieved with these treatment options to date (10); existing protocols including radiochemotherapy with cisplatin, or in cases of epidermal growth factor receptor (EGFR) expression (11), use of EGFR antibodies, have not provided the required therapeutic progress (12). Therefore, advanced treatment strategies should be developed. The molecular interactions of cancer cells are complex and various pathways are involved. This complexity has been described 
by Hanahan and Weinberg as constituting the hallmarks of cancer (13). Cells within a tumour are heterogenous and have different capacities, and various cell reactions to existing therapies may occur; in particular, the capability to invade the surrounding tissue and gain increased metabolism are among the most important functions (14). An important achievement has been the detection of cancer stem cells (CSCs). These cells are considered to be a central element of cancer development, first described in $1997(15,16)$. They have typical stem cell characteristics including self-renewal and differentiation potential and may be responsible for malignant cancer characteristics including resistance to therapy, metastasis and recurrence (17). It has been reported only when CSCs amount to $10 \%$ of cells in a tumour mass that they negatively influence the prognosis of patients (17). An aim of oncology research is to analyse CSCs and their characteristics, first for individual risk stratification, and furthermore to develop targeted therapies. Aldehyde dehydrogenase 1 (ALDH1) is an enzyme located in the cytoplasma and mitochondria. It has been identified in various cancers including glioblastoma and breast cancer, in which it was determined as a predictive marker of worse prognosis $(18,19)$. High expression of ALDH1 was preferential to cells with CSC characteristics (20) and ALDH1 was detected as a CSC marker (CSCM) in HNSCC cell lines (21). Previous study demonstrated a correlation between ALDH1 and oropharyngeal cancers (OPSCCs) and indicated a malignant influence of this CSCM expression on prognosis (22). However to date, to the best of our knowledge, no large-scale comparable studies on OSCC and the expression of ALDH1 have been performed. An aim of the current study was to evaluate ALDH1 expression in HPV+ and - OSCC. The expression of $\mathrm{p} 16^{\mathrm{ink} 4 \mathrm{a}}$, a surrogate marker for HPV detection, and one of the proteins encoded by the cell cycle interacting protein cyclin-dependent kinase inhibitor $2 \mathrm{~A}$ (CDKN2A) gene (23), was a further molecular topic of the present study. DNA methylation, for example associated with smoking, may lead to mutation of the CDKN2A gene and thus $\mathrm{p} 16^{\text {ink4a }}$. This tumour suppressor is established to be mutated in HNSCC and breast and colon cancers (24-26). Recently, interactions of p16 ${ }^{\text {ink } 4 \mathrm{a}}$ have been established to serve functions in regulating CSC and reversing the senescence of CSC during therapy (27). Furthermore, the overexpression of $\mathrm{p} 16^{\text {ink } 4 \mathrm{a}}$ is considered to have negative prognostic influence and promote tumour recurrence and poor survival (28). The current study aim was to evaluate the expression of ALDH1 and p16 ${ }^{\text {ink4a }}$ in OSCC via immunohistochemistry (IHC) and to crosslink expression profiles with clinicopathological data of patients.

\section{Materials and methods}

Participants. The present study involved 186 patients with OSCC. Surgical treatment was performed in the Department of Oral and Maxillofacial Surgery, Klinikum rechts der Isar, Technical University of Munich (Munich, Germany) between January 2009 and December 2012. The surgical treatment included tumour resection, neck dissection with intraoperative margin control and freezing of sections, and primary reconstruction with microvascular flaps. All patients were considered pre- and post-operation at the interdisciplinary conference of head and neck cancer of the university hospital (Klinikum rechts der Isar). The clinical data of all patients was archived, and formalin-fixed and paraffin-embedded tissue was available for all patients. Follow-up examinations were provided to all enrolled patients according to the German S3 guidelines for oral cancer (29). These guidelines recommend that oral cancer patients should be followed up every three months within the first 2 years after primary diagnosis, and then every 6 months in years 3 and 4 of follow-up thereafter. Computer tomographical scans of the head and neck were provided at all second follow-ups. According to the guidelines, the cancer aftercare follow-up aimed to be completed after 5 years of the initial diagnosis. All tumour operations had the intention of curative treatment and included a neck dissection. As intraoperative controls, an intraoperative margin control and frozen sections were also obtained in each tumour operation. As previously described (30), adjuvant cisplatin-based chemoradiation was performed in cases of lymph node metastasis, extracapsular spread, tumour infiltration of the bone, tumours of extended size (T2-T4) and positive microscopic resection margins (R1) according to the S3 German guidelines for oral cancer. Patients were excluded from the study if no curative surgical treatment was performed and the primary treatment was radiochemotherapy. The methods were approved by the Ethical Committee of the Technical University of Munich (approval no. 212108) and in accordance with the Declaration of Helsinki and all patients agreed in writing to the use of their samples for the present research purposes.

Tissue microarray construction (TMA). The centre and invasive front of tumours of all study participants were included in the TMA $(30,31)$. The tissues were formalin-fixed and paraffin-embedded in blocks $(30,31)$. Two pathologists analysed the areas to be represented in the TMA. Two tumour cores from the tumour centre and the invasion front and the corresponding lymph nodes were assembled into the TMA by using a Tissue Microarrayer (Beecher Instruments, Inc., Sun Prairie, WI, USA) as described previously (31).

IHC. p16 ${ }^{\text {ink4a }}$ was stained on the $2-\mu$ m-thick sections from each TMA slide using a p16 ${ }^{\text {ink4a }}$ antibody (cat. no. 725-4713; Ventana Medical Systems, Inc.; Roche, Tucson, AZ, USA) as described previously (30). ALDH1 was also stained on $2-\mu$ m-thick sections from each TMA using an ALDH1 primary antibody (cat. no. 611194; BD Biosciences, San Jose, CA, USA) at a dilution of 1:500. The staining was performed according to the manufacturer's recommendations and as described in the literature (19). Negative and positive controls were stained for both antibodies. For p16 ${ }^{\text {ink } 4 a}$ staining, sections of HPV-negative cervix carcinomas were used as the negative control and HPV-positive cervix carcinoma sections as the positive control. For ALDH1 staining, ALDH1-positive glioblastoma sections were the positive control and urothel carcinoma sections the negative control for this antibody $(30,31)$. The use of control samples followed the approved protocol of the institutional ethics committee and all patients from which control samples were isolated provided informed written consent.

Scoring of ALDH1 and p16 $6^{\text {ink } 4 a}$. The staining was evaluated under a light microscope at a magnification of x200. An international scoring system was used as described previously (32), 
Table I. Baseline clinicopathological characteristics of the OSCC patients $(n=186)$.

\begin{tabular}{lc}
\hline Clinical parameter & Patients \\
\hline Median age, years (range) & $58.68(41.02-85.82)$ \\
Gender & \\
Male/female & $142 / 44$ \\
UICC stage & \\
I & 38 \\
II & 39 \\
III & 29 \\
IVa & 80 \\
Tumour size & \\
T1 & 48 \\
T2 & 78 \\
T3 & 31 \\
T4a & 29 \\
N stage (lymph node metastasis) & \\
N0 & \\
N1 & 73 \\
N2a/b/c & 38 \\
Extracapsular spread & $9 / 37 / 29$ \\
Grading & 10 \\
G1 & \\
G2 & 10 \\
G3 & 33 \\
G4 & 8 \\
\hline & \\
&
\end{tabular}

Values are expressed as number of patients (n) unless otherwise stated. UICC staging (36) was used as indicated. UICC, Union for International Cancer Control.

which incorporated the intensity of the staining as well as the number of stained cells. The staining intensity and cell number were individually scored between 0 and 4 . The intensity score was scored as follows: No staining was scored as 0 , weak staining as 1 , intermediate to weak staining as 2 , intermediate staining as 3 and strong staining as 4 . Positive cell proportion was assigned as 0 if $<10 \%, 1$ if $10-25 \%, 2$ if $25-50 \%, 3$ if $50-75 \%$ and 4 if $>75 \%$, as previously described (31). For each section, the staining intensity and cell proportion scores were then multiplied as described (31). As a result, the subgroup scores 0, 2, 4, 12 and 16 represented ALDH1 staining. Furthermore, based on the staining results, final scores for a positivity cut-off was established for ALDH1. The subgroup scores 12 and 16 were taken to indicate positivity; while the subgroups 0, 2 and 4 were considered to indicate negativity for ALDH1. For p16 ${ }^{\text {ink } 4 a}$, the subgroup scores for positivity were 12 and 16 and for negativity was 0 .

HPV detection. HPV detection was performed on DNA purified from the formalin-fixed, paraffin-embedded (FFPE) tumour tissue (Qiamp DNA FFPE tissue kit; Qiagen $\mathrm{GmbH}$, Hilden, Germany) by polymerase chain reaction, and an HPV
Array kit (HPV 3.5; Zytomed Systems, Berlin, Germany) was used to clarify the HPV subtype, as described previously by our research group (30).

Statistics. SPSS software for Windows, version 23.0 (IBM Corp., Armonk, NY, USA) was used for statistical analysis. The Mann-Whitney $U$ test and $\chi^{2}$ test were used to analyse the data. Survival rates were evaluated by the Kaplan-Meier method and presented as the mean \pm standard deviation and confidence interval (CI). To test for the significance of differences in survival probabilities the log-rank test was used. Risk regression models as the Kruskal Wallis test was used to assess the association of CSCM and p16 ${ }^{\text {ink4a }}$ expression with tumour size and lymph node metastasis. The Cox proportional hazards model was used to analyse multivariate survival rates. $\mathrm{P}<0.05$ was considered to indicate statistical significance.

\section{Results}

Clinical data. Baseline clinical characteristics of the 186 enrolled patients with a diagnosis of OSCC are listed in Table I. Follow-up data revealed the mean survival time of the cohort to be $44.54 \pm 86.81$ months (95\% CI: 32.06-57.02). Survival rate was significantly influenced in cases of lymph node recurrence $(\mathrm{P}=0.020)$. This occurred in 18 patients of the total cohort. In these cases, survival time decreased to $36.31 \pm 21.39$ months (95\% CI: 26.43-46.19). Another notable significant effect on survival rate was observed with regard to local recurrence $(\mathrm{p}=0.027)$, which affected 25 patients, with survival time decreased to $28.49 \pm 23.97$ months $(95 \%$ CI:19.09-37.89). At primary diagnosis, the following aspects had significant influence on overall survival rate; patients with Union for International Cancer Control (UICC) stage III cancer had significantly reduced survival time compared with the cases of stages I and II cancer $(\mathrm{P}=0.003)$, as did patients with UICC stage IV cancer $(\mathrm{P}=0.001)$; patients with $\mathrm{N} 2$ stage cancer had significantly reduced survival time compared with cases of N0 stage cancer $(\mathrm{P}=0.001)$; and stage 4 grading had significant negative influence on survival compared with stage 1-3 grading $(\mathrm{P}=0.001)$ (data not shown).

Association of ALDH1 expression with survival rate. No difference was observed between the different tumour areas regarding positivity for ALDH1 (Fig. 1). Low ALDH1 expression was determined in 24 patients and high expression in 162 patients. Overall survival rates did not differ significantly between the ALDH1-positive cases (44.90土91.40 months; $95 \%$ CI: 30.71-58.93) and the ALDH1-negative cases (41.81 37.83 ; 95\% CI: 26.01-56.83; $\mathrm{P}=0.78)$. High expression of ALDH1 in tumour-infiltrated lymph nodes (ALDH1LN) exhibited an association with more advanced clinicopathological stages compared with low expression of ALDH1: High expression of ALDH1LN was significantly associated with UICC stage IV $(\mathrm{P}=0.044)$ and $\mathrm{T} 4$ stage cancer $(\mathrm{P}=0.03)$. High expression of ALDH1 in the tumour centre and invasive front did not exhibit a significant association (data not shown).

Association of p16 ${ }^{\text {ink } 4 a}$ with survival rate. $\mathrm{p} 16^{\text {ink4a }}$ positivity was detected in 8 cases. The mean survival rate of p16 ${ }^{\text {ink4a }}$-positive patients was $32.38 \pm 11.94$ months (95\% CI: 


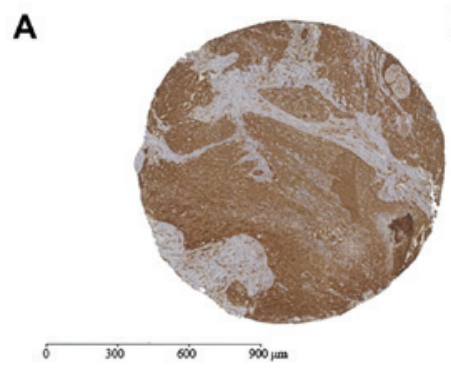

D

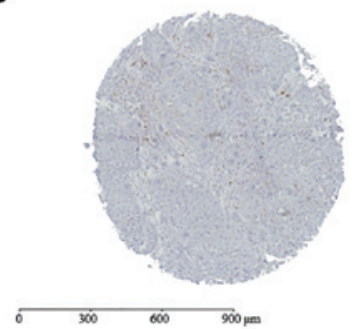

\section{B

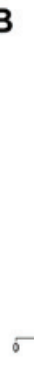

E

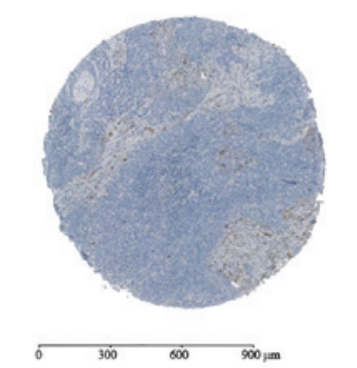

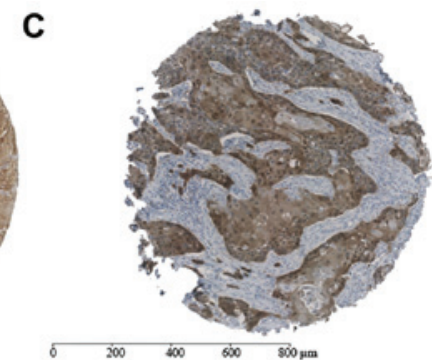

F

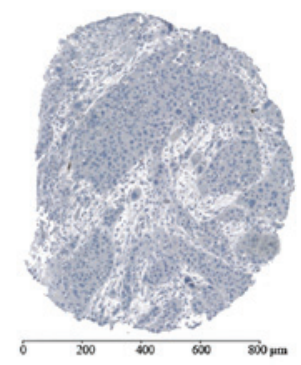

Figure 1. ALDH1 and p16 ${ }^{\text {ink4a }}$ IHC results. Representative samples scored for positive or negative expression are shown. (A) ALDH1-positive score 12; (B) ALDH1-positive score 9; (C) p16 ${ }^{\text {ink4a }}$-positive score; (D) ALDH1-negative score ; (E) ALDH1-negative score 2; (F) p16 ink4a-negative score. ALDH1, aldehyde dehydrogenase 1 ; IHC, immunohistochemistry.

24.11-40.65); no significant difference was determined between the $16^{\text {ink4a }}$-positive and -negative groups $(\mathrm{P}=0.12)$. A total of 5 patients of the cohort tested positive for p16 ${ }^{\text {ink4a }}$ and HPV subtype 16 (for whom mean survival rate was $37.00 \pm 11.35$ months; 95\% CI: 27.05-46.95); no significant difference was determined between the p16 ${ }^{\text {ink } 4 \mathrm{a}}$ and HPV 16 -positive and -negative groups $\mathrm{P}=0.13$ ). A total of 3 patients tested positive for $\mathrm{p}^{\mathrm{ink} 4 \mathrm{a}}$ and negative for HPV (for whom mean survival rate was $24.67 \pm 12.92$ months; 95\% CI: 10.05-39.29); these patients exhibited significantly decreased survival time compared with the mean survival rate of the total cohort $(\mathrm{P}=0.048)$. A total of 178 patients were negative for $\mathrm{p} 16^{\mathrm{ink} 4 \mathrm{a}}$ and HPV and had a mean survival time of 51.16 \pm 41.23 months (CI: 45.12-57.20; compared with the total cohort, $\mathrm{P}=0.35$ ) (data not shown).

Association of ALDH1 and p16 ink4a/HPV with survival rate. A total of 5 of the p16 $6^{\text {ink } 4 a}$-positive cases that also tested HPV-positive exhibited positive ALDH1 expression. This group had a mean survival time of $34.85 \pm 9.29$ months $(95 \%$ CI: 25.56-44.14). The remaining p16 ${ }^{\text {ink } 4 a}$-positive cases with negative ALDH 1 expression $(n=3)$ had a mean survival of 28.26 \pm 12.90 months (95\% CI:13.66-42.86). No significant difference was identified between the survival times of these groups $(\mathrm{P}=0.57)$, or in comparison to the survival times of the whole cohort and the p16 ${ }^{\text {ink4a }}$-positive/ALDH1-positive subgroup $(\mathrm{P}=0.25)$ or the whole cohort and the $\mathrm{p} 16^{\text {ink4a }}$ positive/ALDH1 negative subgroup $(\mathrm{P}=0.15)$. A total of 2 of the HPV-positive patients were ALDH1-negative [mean survival rate, 32.59 \pm 13.85 months;95\% CI:13.34-51.84), while3 exhibited positivity for ALDH1 (mean survival rate, 39.94 \pm 8.02 months; 95\% CI:30.86-49.02); no influence was observed on survival rates between these latter groups $(\mathrm{P}=0.69)$. Additionally, no influence was observed on the survival rates between these latter subgroups and the total cohort $(\mathrm{P}=0.54$ for $\mathrm{ALDH} 1-$ negative and HPV-positive patients; $\mathrm{P}=0.60$ for ALDH1-positive and HPV-positive patients). Lymph node recurrence and local recurrence occurred in one ALDH1-positive, p16 ${ }^{\text {ink4a }}$-positive and HPV-negative case (survival rate, 17.92 months). Isolated local recurrence was diagnosed in one ALDH1-positive, p16 ${ }^{\text {ink } 4 \text { a }}$-positive and HPV-positive case (survival rate, 30.57 months) (data not shown).

\section{Discussion}

CSCs are a major research topic in the field of oncology. These cells may serve as crucial elements in the growth of a tumour mass by providing self-renewal capacity and temporary limited senescence during therapy, recurrence and metastasis (33). With regard to these aspects, patient survival rate may be associated with the expression of CSCMs. Previous literature has reported worse survival rates in cases presenting with high expression of CSCMs, independent of cancer localisation (34). Furthermore, the molecular characteristics of the tumour are considered to have crucial impact on survival (35). The TNM/UICC stage is not always a predictable of outcome at initial diagnosis, since TNM/UICC classification is only based on probabilities and does not take into account cellular features (36). The first step is thus to identify CSCs and subsequently to study the mechanisms that CSCs employ in order to overcome treatment, to supply chemoresistance and to support aggressive tumour behaviour (37;38). Various molecular pathways have been studied in CSC subpopulations. Certain markers on the cell surface have been indicated to be important for migration and epithelial-mesenchymal-transition (EMT) (39). Cluster of differentiation (CD)133 and CD44 have been revealed to be active CSC targets in the process of EMT and have also been identified to be present in HNSCC (40). A further specific CSC molecule is ALDH1 (41), which has demonstrated enriched expression in CSCs of various cancers, and serves a role as an aldehyde-catalysing cytosolic enzyme $(42,43)$. ALDH1-positive CSCs have previously exhibited tumorigenic capacity in HNSCC, which is an important aspect in EMT and linked to metastasis (44). In OPSCC, an association has 
also been detected between the expression of ALDH1 and lymph node metastasis (22). In the ALDH1-positive group in the present study, increased lymph node metastasis was identified, as well as an association with advanced tumour stage compared with the ALDH1-negative group. This highlights the potential aggressiveness of ALDH1 expression in cancer, as suggested previously in the literature (45), and supports the significant association of ALDH1 with lymph node metastasis as reported previously (46). Furthermore, advanced T stages have been reported in ALDH1-positive OSCC cases (47). In particular, an increased number of nodal metastases may be an important indication that CSCs frequently undergo EMT. A negative survival outcome is often discussed in the literature as being associated with enriched ALDH1 cases $(48,49)$. The current study included a limited number of ALDH1-negative cases among the total population, but these exhibited worse survival time than the ALDH1-positive group. However, a significant influence on survival rate in OSCC was not determined from the current results. The lack of a negative survival influence conferred by ALDH1 positivity has also been reported in other studies $(50,51)$. However, with regard to the current study, the lack of a negative survival influence may be attributable to the small number of ALDH1-negative cases and thus to the two groups of ALDH1-positive and -negative cases being comparable only to a minor degree. The scoring of the staining, summarized as positive and negative expression of ALDH1 in the present study, was comparable with that of other studies $(49,52)$. The use of antibody staining for ALDH1 offered clear cut-off values of positivity. Additionally, clear results were also obtained following the staining of $\mathrm{p} 16^{\text {ink4a }}$. The role of $\mathrm{p} 16^{\text {ink4a }}$ expression in cancer is controversial. It has been argued that reduced expression of $\mathrm{p} 16^{\text {ink4a }}$, which is considered largely as a tumour suppressor, leads to worse survival (53); However, the role of over- or underexpression of p16 ${ }^{\text {ink4a }}$ appears to be dependent on cancer subtype (54). Some authors have described enhanced cell migration ability in cases of $\mathrm{p} 16^{\text {ink4a }}$ overexpression (55). This may increase the potential for lymph node metastasis. The current identified relatively few cases of $\mathrm{p} 16^{\text {ink4a }}$-positive OSCC. These cases had significant worse survival in the case of HPV negativity, although no specific clinicopathological features were observed regarding lymph node metastasis and advanced tumour stage. Due to the small number of positive cases for $\mathrm{p} 16^{\text {ink4a }}$, the following conclusions can only be considered as preliminary. Nevertheless, p16 $6^{\text {ink4a }}$ interacts in the cell cycle and it may therefore be suggested that this protein is of importance in OSCC. No association between the expression of ALDH1 and p16 $6^{\text {ink4a }}$ was identified in the present study, indicating the absence of interactions between these two markers. Similar to our previous study (30), the current investigation has indicated that HPV has no influence on survival or cancer stage in OSCC; furthermore, the

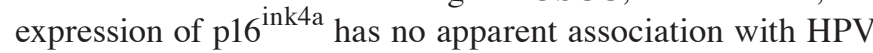
positivity in OSCC.

In conclusion, to the best of our knowledge, the present study is the first to evaluate ALDH1 expression in a large cohort of OSCC patients, and the interaction of $\mathrm{p} 16^{\text {ink4a and }}$ HPV status. The results demonstrate that ALDH1 may serve as a predictive marker for advanced tumour stages, and that it may lead to a tendency for lymph node metastasis in OSCC.
This may be of notable clinical interest since there remains to be no accurate method of predicting lymph node metastasis from radiological findings throughout the clinical disease course. It was further confirmed that HPV status does not have a significant influence on survival rate in OSCC, as previously noted by our group. The expression of $\mathrm{p} 16^{\text {ink4a }}$ was revealed to be associated with worse survival and to serve as a potential predictive marker of survival. As p16 ${ }^{\text {ink4a }}$ exhibits distinct interactions in the cell cycle, further studies on this protein should be performed to assess the various phases of the cell cycle in OSCC. While the current study has some limitations, it may be considered as a successful preliminary study in providing a basis for future studies into the underlying mechanisms involved. Future studies should focus on the evaluation of colony formation among various OSCC cell lines, particularly in the context of the tumour invasive front, to determine the involvement of EMT factors. Detection of ALDH1 at the genomic level may be also important for understanding the role of ALDH1 as a CSCM. The present study nevertheless has identified encouraging preliminary results with regard to the value of ALDH1 as a predictive CSCM for advanced tumour stages in OSCC. The overexpression of $\mathrm{p} 16^{\mathrm{ink} 4 \mathrm{a}}$ in OSCC is a promising future topic for ongoing studies involving evaluation of migratory potential.

\section{Acknowledgements}

The authors are thankful to Dr Melanie Boxberg at the Institute of Pathology, Klinikum rechts der Isar Hospital, Technical University Munich, for providing the tissue microarray, and Daniela Hellmann at the Departement for Obstetrics, Klinikum rechts der Isar, for the technical support. The authors also thank Professor Manfred Schmitt in memoriam, for providing laboratory facilities (Department of Obstetrics, Klinikum rechts der Isar).

\section{Funding}

Not applicable.

\section{Availability of data and materials}

The datasets analysed during the current study are available from the corresponding author on reasonable request.

\section{Authors' contributions}

CG, ED, KDW, OB, CN and AK were responsible for study design. CG and AK conducted the study. CG collected the data. $\mathrm{CG}, \mathrm{OB}$ and $\mathrm{CN}$ analysed the data. $\mathrm{OB}, \mathrm{CG}, \mathrm{ED}$ and $\mathrm{CN}$ interpreted the data. $\mathrm{OB}, \mathrm{CG}, \mathrm{CG}, \mathrm{ED}, \mathrm{KDW}$ and $\mathrm{AK}$ drafted the manuscript. $\mathrm{OB}, \mathrm{CG}, \mathrm{CG}, \mathrm{ED}, \mathrm{KDW}$ and $\mathrm{AK}$ provided manuscript content. CG, KDW and AK reviewed the integrity of the data analysis. All authors approved the final version of the manuscript.

\section{Ethics approval and consent to participate}

The study was approved by the Ethical Committee of the Technical University of Munich, Munich, Germany (approval 
no. 212108) and all patients provided written informed consent for the use of relevant samples.

\section{Consent for publication}

Consent for publication was agreed upon in the written consent forms signed by the patients.

\section{Competing interests}

The authors declare that they have no competing interests.

\section{References}

1. La Torre G, Kirch W, Bes-Rastrollo M, Ramos RM, Czaplicki M, Gualano MR, Thümmler K, Ricciardi W and Boccia A; GHPSS Collaborative Group: Tobacco use among medical students in Europe: Results of a multicentre study using the Global Health Professions Student Survey. Public Health 126: 159-164, 2012.

2. Arantes LM, de Carvalho AC, Melendez ME, Carvalho AL and Goloni-Bertollo EM: Methylation as a biomarker for head and neck cancer. Oral Oncol 50: 587-592, 2014.

3. Kumar B, Cordell KG, Lee JS, Worden FP, Prince ME, Tran HH, Wolf GT, Urba SG, Chepeha DB, Teknos TN, et al: EGFR, p16, HPV Titer, Bcl-xL and p53, sex, and smoking as indicators of response to therapy and survival in oropharyngeal cancer. J Clin Oncol 26: 3128-3137, 2008.

4. Kolk A, Wermker K, Bier H, Götz C and Eckert AW: Current surgical and adjuvant therapy concepts of malignant tumors of the facial skin and the pinna. Laryngorhinootologie 94: 77-85, 2015 (In German).

5. Fakhry C, Sugar E, D'Souza G and Gillison M: Two-week versus six-month sampling interval in a short-term natural history study of oral HPV infection in an HIV-positive cohort. PLoS One 5 : e11918, 2010

6. Bagan JV and Scully C: Recent advances in Oral Oncology 2007: Epidemiology, aetiopathogenesis, diagnosis and prognostication. Oral Oncol 44: 103-108, 2008.

7. Lindenblatt RC, Martinez GL, Silva LE, Faria PS, Camisasca DR and Lourenço SQ: Oral squamous cell carcinoma grading systems - analysis of the best survival predictor. J Oral Pathol Med 41: 34-39, 2012.

8. Mücke T, Koschinski J, Wolff KD, Kanatas A, Mitchell DA, Loeffelbein DJ, Deppe H and Rau A: Quality of life after different oncologic interventions in head and neck cancer patients. J Craniomaxillofac Surg 43: 1895-1898, 2015.

9. González-García R, Naval-Gías L, Román-Romero L Sastre-Pérez J and Rodríguez-Campo FJ: Local recurrences and second primary tumors from squamous cell carcinoma of the oral cavity: A retrospective analytic study of 500 patients. Head Neck 31: 1168-1180, 2009.

10. Park MJ, Roh JL, Kim SB, Choi SH, Nam SY and Kim SY: Prognostic value of circulating biomarker score in advanced-stage head and neck squamous cell carcinoma. Eur J Cancer 92: 69-76, 2018.

11. Thomas SM, Bhola NE, Zhang Q, Contrucci SC, Wentzel AL, Freilino ML, Gooding WE, Siegfried JM, Chan DC and Grandis JR: Cross-talk between G protein-coupled receptor and epidermal growth factor receptor signaling pathways contributes to growth and invasion of head and neck squamous cell carcinoma. Cancer Res 66: 11831-11839, 2006.

12. Kalyankrishna S and Grandis JR: Epidermal growth factor receptor biology in head and neck cancer. J Clin Oncol 24 2666-2672, 2006

13. Fouad YA and Aanei C: Revisiting the hallmarks of cancer. Am J Cancer Res 7: 1016-1036, 2017.

14. Magee JA, Piskounova E and Morrison SJ: Cancer stem cells: Impact, heterogeneity, and uncertainty. Cancer Cell 21: 283-296, 2012.

15. Singh A and Settleman J: EMT, cancer stem cells and drug resistance: An emerging axis of evil in the war on cancer. Oncogene 29: 4741-4751, 2010.

16. Hanahan D and Weinberg RA: The hallmarks of cancer. Cell 100: 57-70, 2000

17. Nguyen LV, Vanner R, Dirks P and Eaves CJ: Cancer stem cells: An evolving concept. Nat Rev Cancer 12: 133-143, 2012.
18. Knudsen ES, Dervishaj O, Kleer CG, Pajak T, Schwartz GF and Witkiewicz AK: EZH2 and ALDH1 expression in ductal carcinoma in situ: Complex association with recurrence and progression to invasive breast cancer. Cell Cycle 12: 2042-2050, 2013.

19. Schäfer A, Teufel J, Ringel F, Bettstetter M, Hoepner I, Rasper M, Gempt J, Koeritzer J, Schmidt-Graf F, Meyer B, et al: Aldehyde dehydrogenase 1A1 - a new mediator of resistance to temozolomide in glioblastoma. Neuro-oncol 14: 1452-1464, 2012.

20. Reid P, Wilson P, Li Y, Marcu LG, Staudacher AH, Brown MP and Bezak E: In vitro investigation of head and neck cancer stem cell proportions and their changes following X-ray irradiation as a function of HPV status. PLoS One 12: e0186186, 2017.

21. Campos MS, Neiva KG, Meyers KA, Krishnamurthy S and Nör JE: Endothelial derived factors inhibit anoikis of head and neck cancer stem cells. Oral Oncol 48: 26-32, 2012.

22. Qian X, Wagner S, Ma C, Klussmann JP, Hummel M, Kaufmann AM and Albers AE: ALDH1-positive cancer stem-like cells are enriched in nodal metastases of oropharyngeal squamous cell carcinoma independent of HPV status. Oncol Rep 29: 1777-1784, 2013.

23. Sritippho T, Pongsiriwet S, Lertprasertsuke N, Buddhachat K, Sastraruji T and Iamaroon A: p16 - a Possible Surrogate Marker for High-Risk Human Papillomaviruses in Oral Cancer? Asian Pac J Cancer Prev 17: 4049-4057, 2016.

24. Hoesli R, Birkeland AC, Rosko AJ, Issa M, Chow KL, Michmerhuizen NL, Mann JE, Chinn SB, Shuman AG, Prince ME, et al: Proportion of CD4 and CD8 tumor infiltrating lymphocytes predicts survival in persistent/recurrent laryngeal squamous cell carcinoma. Oral Oncol 77: 83-89, 2018.

25. Alipoor FJ, Asadi MH and Torkzadeh-Mahani M: MIAT lncRNA is overexpressed in breast cancer and its inhibition triggers senescence and G1 arrest in MCF7 cell line. J Cell Biochem, $18 \mathrm{Jan}, 2018$ (Epub ahead of print).

26. Zhao P, Hu YC and Talbot IC: Expressing patterns of p16 and CDK4 correlated to prognosis in colorectal carcinoma. World J Gastroenterol 9: 2202-2206, 2003.

27. Milanovic M, Fan DNY, Belenki D, Däbritz JHM, Zhao Z, Yu Y, Dörr JR, Dimitrova L, Lenze D, Monteiro Barbosa IA, et al: Senescence-associated reprogramming promotes cancer stemness. Nature 553: 96-100, 2018.

28. Okuma A, Hanyu A, Watanabe S and Hara E: p16 ${ }^{\text {Ink4a }}$ and p21Cip1/Waf1 promote tumour growth by enhancing myeloid-derived suppressor cells chemotaxis. Nat Commun 8: 2050, 2017.

29. Wolff KD, Follmann M and Nast A: The diagnosis and treatment of oral cavity cancer. Dtsch Arztebl Int 109: 829-835, 2012.

30. Götz C, Drecoll E, Straub M, Bissinger O, Wolff KD and Kolk A: Impact of HPV infection on oral squamous cell carcinoma. Oncotarget 7: 76704-76712, 2016.

31. Bissinger O, Kolk A, Drecoll E, Straub M, Lutz C, Wolff KD and Götz C: EGFR and Cortactin: Markers for potential double target therapy in oral squamous cell carcinoma. Exp Ther Med 14: 4620-4626, 2017

32. Remmele W and Stegner HE: Recommendation for uniform definition of an immunoreactive score (IRS) for immunohistochemical estrogen receptor detection (ER-ICA) in breast cancer tissue. Pathologe 8: 138-140, 1987.

33. La Porta CA, Zapperi S and Sethna JP: Senescent cells in growing tumors: Population dynamics and cancer stem cells. PLOS Comput Biol 8: e1002316, 2012.

34. Reya T, Morrison SJ, Clarke MF and Weissman IL: Stem cells, cancer, and cancer stem cells. Nature 414: 105-111, 2001.

35. Solomon I, Voiculescu VM, Caruntu C, Lupu M, Popa A, Ilie MA, Albulescu R, Caruntu A, Tanase C, Constantin C, et al: Neuroendocrine Factors and Head and Neck Squamous Cell Carcinoma: An Affair to Remember. Dis Markers 2018: 9787831, 2018.

36. Burke HB: Outcome prediction and the future of the TNM staging system. J Natl Cancer Inst 96: 1408-1409, 2004.

37. Bao S, Wu Q, McLendon RE, Hao Y, Shi Q, Hjelmeland AB, Dewhirst MW, Bigner DD and Rich JN: Glioma stem cells promote radioresistance by preferential activation of the DNA damage response. Nature 444: 756-760, 2006.

38. Magni M, Shammah S, Schiró R, Mellado W, Dalla-Favera R and Gianni AM: Induction of cyclophosphamide-resistance by aldehyde-dehydrogenase gene transfer. Blood 87: 1097-1103, 1996.

39. Mani SA, Guo W, Liao MJ, Eaton EN, Ayyanan A, Zhou AY, Brooks M, Reinhard F, Zhang CC, Shipitsin M, et al: The epithelial-mesenchymal transition generates cells with properties of stem cells. Cell 133: 704-715, 2008. 
40. Boxberg M, Jesinghaus M, Dorfner C, Mogler C, Drecoll E, Warth A, Steiger K, Bollwein C, Meyer P, Wolff KD, et al: Tumour budding activity and cell nest size determine patient outcome in oral squamous cell carcinoma: Proposal for an adjusted grading system. Histopathology 70: 1125-1137, 2017.

41. Wu J, Mu Q, Thiviyanathan V, Annapragada A and Vigneswaran N: Cancer stem cells are enriched in Fanconi anemia head and neck squamous cell carcinomas. Int J Oncol 45: 2365-2372, 2014.

42. Ikawa M, Impraim CC, Wang G and Yoshida A: Isolation and characterization of aldehyde dehydrogenase isozymes from usual and atypical human livers. J Biol Chem 258: 6282-6287, 1983.

43. Resetkova E, Reis-Filho JS, Jain RK, Mehta R, Thorat MA, Nakshatri H and Badve S: Prognostic impact of ALDH1 in breast cancer: A story of stem cells and tumor microenvironment. Breast Cancer Res Treat 123: 97-108, 2010.

44. Clay MR, Tabor M, Owen JH, Carey TE, Bradford CR, Wolf GT, Wicha MS and Prince ME: Single-marker identification of head and neck squamous cell carcinoma cancer stem cells with aldehyde dehydrogenase. Head Neck 32: 1195-1201, 2010.

45. Visvader JE and Lindeman GJ: Cancer stem cells in solid tumours: Accumulating evidence and unresolved questions. Nat Rev Cancer 8: 755-768, 2008.

46. Xu J, Müller S, Nannapaneni S, Pan L, Wang Y, Peng X, Wang D, Tighiouart M, Chen Z, Saba NF, et al: Comparison of quantum dot technology with conventional immunohistochemistry in examining aldehyde dehydrogenase $1 \mathrm{~A} 1$ as a potential biomarker for lymph node metastasis of head and neck cancer. Eur J Cancer 48: 1682-1691, 2012.

47. He KF, Zhang L, Huang CF, Ma SR, Wang YF, Wang WM, Zhao ZL, Liu B, Zhao YF, Zhang WF, et al: CD163+ tumor-associated macrophages correlated with poor prognosis and cancer stem cells in oral squamous cell carcinoma. BioMed Res Int 2014: 838632, 2014.

48. Ginestier C, Hur MH, Charafe-Jauffret E, Monville F, Dutcher J, Brown M, Jacquemier J, Viens P, Kleer CG, Liu S, et al: ALDH1 is a marker of normal and malignant human mammary stem cells and a predictor of poor clinical outcome. Cell Stem Cell 1: 555-567, 2007.

49. Rasper M, Schäfer A, Piontek G, Teufel J, Brockhoff G, Ringel F, Heindl S, Zimmer C and Schlegel J: Aldehyde dehydrogenase 1 positive glioblastoma cells show brain tumor stem cell capacity. Neuro-oncol 12: 1024-1033, 2010
50. Bednarz-Knoll N, Nastały P, Żaczek A, Stoupiec MG, Riethdorf S, Wikman H, Müller V, Skokowski J, Szade J, Sejda A, et al: Stromal expression of ALDH1 in human breast carcinomas indicates reduced tumor progression. Oncotarget 6: 26789-26803, 2015.

51. Morimoto K, Kim SJ, Tanei T, Shimazu K, Tanji Y, Taguchi T, Tamaki Y, Terada N and Noguchi S: Stem cell marker aldehyde dehydrogenase 1-positive breast cancers are characterized by negative estrogen receptor, positive human epidermal growth factor receptor type 2, and high Ki67 expression. Cancer Sci 100: 1062-1068, 2009.

52. Alamgeer M, Ganju V, Kumar B, Fox J, Hart S, White M, Harris M, Stuckey J, Prodanovic Z, Schneider-Kolsky ME, et al: Changes in aldehyde dehydrogenase-1 expression during neoadjuvant chemotherapy predict outcome in locally advanced breast cancer. Breast Cancer Res 16: R44, 2014.

53. Sharpless NE: INK4a/ARF: A multifunctional tumor suppressor locus. Mutat Res 576: 22-38, 2005.

54. Emig R, Magener A, Ehemann V, Meyer A, Stilgenbauer F, Volkmann M, Wallwiener D and Sinn HP: Aberrant cytoplasmic expression of the p16 protein in breast cancer is associated with accelerated tumour proliferation. Br J Cancer 78: 1661-1668, 1998.

55. Chen YW, Chu HC, Ze-Shiang Lin, Shiah WJ, Chou CP, Klimstra DS and Lewis BC: p16 Stimulates CDC42-dependent migration of hepatocellular carcinoma cells. PLoS One 8: e69389, 2013. 